\title{
PERCEPCIÓN Y MIEDO AL CRIMEN: REVISIÓN DE ARTÍCULOS EN ESPAÑOL 2004-2014 1
}

\section{PERCEPTION AND FEAR OF CRIME: A REVIEW OF ARTICLES IN SPANISH 2004-2014}

\author{
Juan Diego García-Castro ${ }^{2}$ \\ juandiego.garcia@ucr.ac.cr \\ Beatriz Barrantes Umaña ${ }^{3}$ \\ beatriz.barrantesumana@ucr.ac.cr
}

Fecha de recepción: 23 de junio de 2015 - Fecha de aceptación: 12 de mayo de 2016

\begin{abstract}
Resumen
Se realiza una revisión bibliográfica de artículos científicos en español de psicología social sobre percepción y miedo a la criminalidad, publicados durante la década del 2004 al 2014 en las bases de datos Redalyc, Dialnet, Scielo y Google Académico. Se encontraron 52 artículos. A partir de un análisis de contenido se agruparon los estudios en cinco categorías: perspectivas críticas, miedo al crimen, medición de la criminalidad, percepción de la criminalidad y medios de comunicación. Los resultados señalan que la investigación se ha caracterizado por una visión crítica y descriptiva del tema. Se discute la necesidad de prestar mayor atención a las mediciones y el impacto del miedo al crimen, diferenciar conceptualmente y metodológicamente la percepción del miedo, y estudiar modelos cuasi-experimentales que prueben intervenciones de reducción del miedo y beneficien la salud mental.

Palabras claves: Criminalidad, Percepción, Miedo, Psicología Social y Revisión Bibliográfica
\end{abstract}

\begin{abstract}
This is a literature review of social psychology scientific articles, in Spanish, on perception and fear of crime that were published from 2004 to 2014 on Redalyc, Dialnet, Scielo and Google Scholar databases. Fifty-two articles were found and they were grouped by content analysis into five categories: critical perspectives, fear of crime, measurement of crime, perceptions of crime, and mass media. Results indicated that research has been characterized by critical and descriptive perspectives. The discussion section highlights the need to pay greater attention to the measurements and the impact of fear of crime as well as differentiating, conceptually and methodologically, the perception of fear. In addition, studying quasi-experimental designs that test interventions to reduce fear and benefit the mental health of inhabitants is needed.
\end{abstract}

Key words: Criminality, Perception, Fear, Social Psychology and Literature Review

1 El artículo es producto de la investigación 540-B3-320 “Criminalidad en Costa Rica: clases sociales, ideología y victimización. Un análisis psicosocial”, financiada por la Sede de Occidente y la Vicerrectoría de Investigación de la Universidad de Costa Rica.

2 Sede de Occidente, Universidad de Costa Rica.

3 Sede de Occidente, Universidad de Costa Rica. 


\section{Introducción}

La criminalidad es uno de los principales problemas de América Latina. Se cuenta con regiones establecidas como las más peligrosas del mundo, al año se producen alrededor de 450000 asesinatos y muchos de los crímenes quedan impunes (PNUD, 2013).

De tal forma, el presente trabajo busca hacer una revisión bibliográfica de artículos científicos en español de psicología social, sobre percepción y miedo a la criminalidad publicados durante la década del 2004 al 2014 en las bases de datos Redalyc, Dialnet, Scielo y Google Académico.

Ahora bien, se debe notar que a pesar de ser de unas de las principales preocupaciones de los habitantes latinoamericanos, la producción científica regional sobre el tema se ha caracterizado por la dispersión (Gómez, 2013). Por ello, este artículo busca recopilar, describir y analizar esta información para contribuir en la profundización del estudio psicosocial de la criminalidad en contextos hispanoparlantes.

En América Latina la inseguridad ha ocupado el vacío que han dejado las políticas de bienestar social. La inseguridad se intenta cubrir con seguridad policial, que coloca a la criminalidad como una de las principales claves para interpretar la realidad (Fonseca y Sandoval, 2005). Sin embargo, la sensación de inseguridad no proviene del aumento de hechos criminales sino del aumento en la oferta de los medios de comunicación sobre este tipo de noticias.

El discurso de la criminalidad es parte de un discurso ideológico que no corresponde necesariamente con la experiencia real. El cambio en el modelo de desarrollo ha producido un cambio en el discurso. El neoliberalismo necesita una mayor criminalización para justificar sus políticas de control social (Muñoz, 2012). En los últimos años el discurso de la criminalidad en Costa Rica ha aumentado sin precedentes y ha justificado mayor inversión económica en la fuerza pública, permisos para que barcos militares estadounidenses patrullen los mares y que haya mayor presencia policial en la vía pública y en los lugares que habitan las clases populares (Huhn, 2008).

La psicología social se centra en el estudio de estos temas, enfocándose en el estudio científico de la acción en cuanto ideológica. Se entiende la ideología como un conjunto de representaciones y creencias sociales compartidas por un grupo de personas. Son procesos básicos de la cognición social de los individuos, su objetivo es ordenar las representaciones mentales, controlar las creencias personales y sociales, incidir sobre el comportamiento, justificar el orden social y legitimarlo como válido para todos (as) (Martín-Baro, 1983/2004).

La percepción es un proceso psicológico básico a través del cual la persona recibe a través de todos los sentidos imágenes, impresiones o sensaciones para conocer el mundo. Con relación a la percepción de criminalidad es entendida como el grado de sospecha personal hacia supuestos asaltantes o delincuentes (Cruz, 2012), esto surge a partir de actos criminales que se han cometido hacia personas conocidas o desconocidas, casas o negocios.

Por otro lado, el miedo ha sido parte del ser humano desde su constitución biológica, es un elemento subjetivo que no se observa a simple vista pero que se manifiesta bajo ciertas condiciones, como una expresión que altera, perturba y trastorna a la persona (Méndez, et al, 2009); también este sentimiento se puede incrementar o reducir en cada uno de los sujetos al ser una condición socialmente creada. El miedo, como una parte natural del ser humano, se encuentra siempre presente en los distintos ámbitos en los que se desenvuelve la persona y nunca la abandona

Se ha definido el miedo al crimen como un sentimiento de ansiedad y peligro ante las posibilidades que se tiene de ser víctima de un delito o acto criminal (Ruíz, 2007). Esta definición permite identificar dos elementos del miedo al delito, de un lado se encuentra la emoción de miedo, y del otro, la posibilidad percibida de victimización o de sufrir un delito.

La clase social hegemónica instrumentaliza el miedo a la criminalidad provocado por los medios de comunicación para favorecer sus intereses (Chomsky, 2002). El estudio comprometido con la 
cotidianidad de las sociedades que habitamos, tiene entre sus tareas básicas conocer con amplitud cómo las personas en nuestro contexto perciben, evalúan y sienten estos fenómenos.

Para ello, se revisa la literatura sobre el tema producida en la región durante la última década. A partir de esta revisión se crean categorías que agrupan los principales hallazgos obtenidos hasta el momento. Finalmente, se hace un balance del conocimiento adquirido y se señalan cuáles son los principales desafíos con los que contamos en la actualidad.

\section{Método}

\section{Diseño}

La revisión bibliográfica incluye artículos en español de revistas indexadas, los cuales se encontraron en las bases de datos Redalyc, Scielo, Dialnet y Google Académico. Se utilizaron dichas bases de datos por ser de las principales fuentes de consulta de acceso abierto en Iberoamérica (Guédon, 2011).

\section{Búsqueda de artículos}

Se restringió la búsqueda de artículos científicos publicados durante el período 2004-2014 y de acceso abierto. Se realizaron ocho combinaciones de búsquedas con las palabras claves: percepción y criminalidad, percepción y crimen, percepción y delincuencia; y percepción y (e) inseguridad. Además, miedo y criminalidad, miedo y crimen, miedo y delincuencia; y miedo e inseguridad.

En la base de datos Redalyc se utilizó la opción de búsqueda avanzada y se buscaron las palabras claves en el título y dentro de las palabras claves de los artículos. Asimismo, en la disciplina y el país se utilizó la opción de cualquiera. En el caso de Scielo, se hicieron las búsquedas de las palabras con el método integrado y por palabra, y con la opción regional.

En Dialnet se buscaron las ocho combinaciones de palabras clave sin ninguna otra especificación. Por último, en Google Académico se utilizó la opción de búsqueda avanzada, se hicieron las búsquedas de las palabras en los títulos de los artículos y no se utilizó el conector " $y$ " entre las palabras.

Con el resultado de dichas búsquedas, se escogieron los artículos con base en los siguientes criterios. Criterios de inclusión: artículos científicos con recolección de datos empíricos (cualitativos y cuantitativos) o revisiones bibliográficas de producción académica, de América Latina o de España, de revistas indexadas y que trataran un tema de psicología social. Los criterios de exclusión fueron: que sean ensayos, reseñas de libros o libros, que no fueran de América Latina o de España, ni de revistas indexadas y que no trataran un tema de psicología social. Por ejemplo, no se incluyeron artículos de páginas de internet, trabajos de cursos universitarios o trabajos sin publicar.

\section{Procedimientos}

En primera instancia, se recolectaron los artículos. Una vez reunidos, se procedió a resumirlos y clasificarlos según temas en común y estos dieron paso a cada categoría.

\section{Análisis}

Se usaron técnicas de análisis de contenido para identificar los artículos a incluir, y para construir sus categorías de clasificación. El análisis de contenido consistió en revisar el tema de cada artículo, su importancia, los temas en común y los temas diferentes. Así mismo, se utilizó análisis de frecuencias para cuantificar los artículos según categoría, país de publicación y revista. 


\section{Resultados}

En la tabla 1 se describe la cantidad de artículos que se recolectaron según la categoría de análisis a la que pertenecen.

Tabla 1

Artículos de percepción y miedo a la criminalidad por área temática

\begin{tabular}{lcc}
\hline Área temática & N (52) & $\%$ \\
\hline Perspectivas críticas & 13 & 25 \\
Miedo al crimen & 12 & 23 \\
Medición de la criminalidad & 10 & 19,2 \\
Percepción de criminalidad & 9 & 17,3 \\
Medios de comunicación & 8 & 15,4 \\
\hline
\end{tabular}

Elaboración propia.

En total se utilizaron 52 artículos, de los cuales "perspectivas críticas" ( $\mathrm{N}=13,25 \%)$ y "miedo al crimen" ( $\mathrm{N}=12,23 \%)$ alcanzaron una mayor concentración en los trabajos, seguidos de "medición de la criminalidad" $(\mathrm{N}=10,19,2 \%)$ y "percepción de criminalidad" $(\mathrm{N}=9,17,3 \%)$, por último "medios de comunicación" ( $\mathrm{N}=8,15,3 \%)$. Dentro de las revistas más utilizadas destacan el "Boletín de Psicología" de la que se extrajeron 4 artículos, del "Acta Colombiana de Psicología" y la "Revista Española de Investigación Criminológica" se utilizaron 3 artículos, mientras que de las revistas "International E-Journal of Criminal Sciences", "Quórum Académico", "Eure”, "Revista electrónica de Ciencia Penal y Criminología", "Revista de Ciencias Sociales" y "Cuadernos de información" se utilizaron 2 artículos.

En la tabla 2 una síntesis de los resultados: 
Perspectivas críticas. Se encontraron cinco corrientes críticas. La primera es que el tema de la criminalidad no ocupa las meditaciones diarias de las personas en América Latina, a menos que ocurra un hecho cuya importancia sea de gran magnitud para que los medios de comunicación le presten atención (Molina, 2005). La violación de la ley y el uso de la cárcel, como recurso sancionador, no son las prioridades en las campañas electorales. Tampoco lo es el mejoramiento de las condiciones de vida de la población penal o de los sistemas de justicia penal

Otra corriente crítica es que la criminalidad ha sido utilizada por las clases dominantes para mantener el control sobre las grandes minorías. El discurso de la criminalidad es un discurso ideológico que no corresponde con lo que sucede en la realidad (Huhn, 2008). Las clases dominantes controlan el discurso público y generan un sentimiento de inseguridad común (García-Castro, 2012). El miedo al crimen y la inseguridad ciudadana se ha convertido en una de las principales herramientas de control social, (Amaya, Espinoza y Vozmediano, 2011), ya que tiene como consecuencia la proliferación de sentimientos de sometimiento y conservadurismo. El nivel de miedo al delito es mayor en comparación con las cifras reales de criminalidad. Sin embargo, el discurso de que el crimen aumenta día con día sigue siendo utilizado a conveniencia de unos (as) pocos (as) (Varela, 2005).

Por otro lado, una crítica que la inseguridad no se da por la falta de protección sino más bien, que la inseguridad ha provocado que las personas busquen una forma de protegerse y sentirse seguras(os). Por lo tanto, la búsqueda de protección paradójicamente estaría provocando el sentimiento de inseguridad en los individuos (San Martín, 2013).

Una cuarta perspectiva explica las diferentes consecuencias que experimentan las mujeres en comparación con los hombres a raíz del nivel de temor al crimen. Los artículos encontrados respaldan que las mujeres experimentan mayor inseguridad en comparación con los hombres. Esta mayor sensación de inseguridad de las mujeres, generalmente, se deriva de su sensibilidad a la violación. Las mujeres temen a delitos como homicidios y asaltos armados en la vía pública o en el hogar; a pesar de que los datos muestran que su posibilidad de ser víctimas de asaltos es más baja en comparación a los hombres (Varela, 2008). Sin embargo, el nivel de temor existe porque las mujeres temen que estos crímenes pueden traer como consecuencia una violación.

La quinta corriente del análisis crítico de la criminalidad se basa en analizar su influencia en el sistema político. Se explica cómo el miedo y la violencia han sido utilizados por los gobiernos como estrategias para manipular a la ciudadanía. Se hace referencia a la relación que hay entre la ideología política y el miedo al crimen. La inseguridad genera la movilización de dos emociones básicas: miedo y malestar. El miedo se da por la posibilidad de ser víctima de actos delictivos y el malestar porque se percibe al Estado como responsable de proporcionar seguridad (Valdez y Paniagua, 2011).

Por último, las personas aceptan el uso de la violencia para combatir el crimen por dos razones. La primera menciona que las personas basadas en el temor de ser victimizadas aceptan este tipo de medidas a pesar de sacrificar algunos de sus derechos. La segunda explica que se acepta el uso de la violencia sólo contra los grupos que son construidos como enemigos (Becerra y Trujano, 2011).

\section{Miedo al crimen}

Según Restrepo y Moreno (2007), existen tres tesis sobre el miedo al delito. En la primera se establece que es producto de la victimización. El miedo al crimen es producto de la experiencia directa o de forma indirecta por medio de allegados (-as). La segunda es la tesis del control social y postula que el miedo se genera por la inhabilidad de un individuo de controlar su propia vida y los comportamientos y actividades de los y las demás. La gente tiene miedo por su incapacidad de prevenir o poder manejar las consecuencias de la victimización.

Finalmente, se habla de la tesis del entorno urbano, que atribuye el miedo al crimen a la manera en que la gente experimenta e interpreta el entorno urbano que lo rodea, "el entorno urbano le da a un individuo la experiencia visual (cuando el conocimiento real es limitado) sobre la probabilidad del 
riesgo al crimen y la posibilidad de que otros intervengan para ayudarlo" (Restrepo y Moreno, p.169). Las investigaciones señalan que el miedo al crimen es un fenómeno urbano en su origen (Vozmediano, Vergara y San Juan, 2010), debido a que es en las ciudades donde este miedo es más frecuente, y donde se manifiestan en mayor medida sus repercusiones.

Se ha mostrado también que el miedo al delito está asociado con una serie de consecuencias tanto a nivel individual como sociales. Las individuales son el empobrecimiento de la salud mental, por fallas de la empatía y el aumento de la desconfianza hacia las otras personas, desarrollo de cuadros patológicos como depresión y ansiedad; reducciones en el funcionamiento físico debido a limitaciones en actividades físicas y recreativas; cambios en la conducta que afectan el estilo y la calidad de vida como adoptar mayores medidas de autoprotección; fractura del sentido de comunidad, abandono de espacios públicos y apoyo a medidas represivas (Muratori y Zubieta, 2013).

El miedo ha provocado grandes cambios en los espacios físicos. Hay una mayor proliferación de los espacios cerrados, las familias han cambiado los espacios que tradicionalmente habían sido entendidos como públicos por espacios privados. Algunos ejemplos de estos cambios son la creación de los centros comerciales, conjuntos habitacionales y otros que prestan algún servicio en espacios cerrados o amurallados, esta situación los hace aparecer como lugares que ofrecen más protección o seguridad ante el entorno incierto o amenazante (Méndez, Villar y Becerril, 2009). Es cada vez más común ver dispositivos de seguridad, rejas, puertas blindadas, letreros de prevención, anuncios de peligro, alambres electrificados, establecimiento de límites, que van desde las barras móviles en la entrada del conjunto habitacional hasta la vigilancia con equipo sofisticado de seguridad.

\section{Medición de la criminalidad}

El instrumento que se ha usado con mayor frecuencia ha sido la encuesta. A pesar de que también se han llevado a cabo estudios cualitativos, que tienen como objeto profundizar en uno u otro(s) aspecto(s) del fenómeno (Vozmediano, 2010). El uso de cuestionarios aplicables a un número significativo de participantes ofrece ventajas como la posibilidad de diagnosticar el alcance del fenómeno y construir modelos explicativos generalizables a la población.

Sin embargo, los trabajos que se realizan con una metodología de encuesta han afrontado dos problemas significativos. El primero se refiere a una falta de acuerdo en la definición y 'operacionalización' del miedo al delito. El segundo problema radica en el uso de medidas poco precisas, lo cual constituye una amenaza a la validez (Sillano, Greene y Ortúzar, 2006; Vozmediano, 2010).

Aun así se han construido diversas medidas para el miedo al crimen que intentan superar estas limitaciones. Por ejemplo, el Cuestionario de Inseguridad Urbana (CIU) el cual recoge respuestas o reacciones pertenecientes a los sistemas afectivo, cognitivo, fisiológico y conductual (Vuanello, 2006).

Otro instrumento que se ha utilizado ha sido la tecnología SIG (Sistemas de Información Geográfica), la cual se emplea para la recopilación, representación y análisis de todo tipo de información referenciada geográficamente. Bases de datos de este tipo se emplean para la elaboración de "mapas del delito", que muestran cómo se distribuyen distintos tipos de delitos por la ciudad, y permiten relacionar ese patrón con otras variables (Vozmediano y San Juan, 2006).

Ruiz (2007) menciona que para que las encuestas sobre el crimen sean válidas y confiables estas se deben concentrar en pocos delitos. Las encuestas en las que se toman en cuenta todos los crímenes arrojan resultados en los cuales se ven grandes disminuciones en la incidencia del crimen. Sin embargo, lo que disminuye son los delitos poco comunes, alterando los datos, por lo que los resultados no representan la realidad tal y como es. Otra recomendación es retomar las vertientes ambientales, sociales y físicas, con el fin de que la medición sea más completa y precisa. Además, las 'operacionalizaciones' del miedo al delito deben referirse al constructo del miedo, en lugar de preguntar por una sensación de preocupación ambigua, y deben hacer referencia al crimen o delito, para que la definición sea clara y correspondiente al constructo (Ruíz, 2010). 


\section{Percepción de criminalidad}

Existen varias teorías que buscan explicar la percepción de criminalidad. Una de ellas es la teoría de la construcción social de la realidad, la cual fue propuesta inicialmente por Berger y Luckmann (1969, como se citó en Huhn, 2008). Según esta, la violencia, en el nivel individual, es uno de los fenómenos físicos más inmediatos y más reales. Pero al mismo tiempo, la violencia y la percepción del crimen son construcciones sociales. Puede que una persona reaccione frente a un acto físico y real de violencia, pero una sociedad, en cambio, define y construye más bien un fenómeno social, en la medida en que le atribuye a este una determinada importancia.

La segunda teoría es la del discurso según Foucault (1997, 2003, 2005, como se citó en Huhn, 2008) o también Bourdieu (1990, 1992, como se citó en Huhn, 2008). Para estos autores, la percepción social de los problemas es transmitida mediante el discurso. Los discursos son actos de habla estructurados que producen una realidad. Un discurso se genera en numerosos espacios discursivos en los que diferentes actores compiten por la definición e interpretación de varios fenómenos particulares.

La tercera teórica explica que la percepción de la criminalidad se debe al lazo cultural de confianza y violencia. Esta fue propuesta por Reemtsma (2008, como se citó en Huhn, 2008), quien señala que el lazo cultural de confianza y violencia es una constelación específica de la modernidad. La confianza es una de las calidades más importantes en las sociedades modernas, que une a la sociedad y reduce la criminalidad. Por ejemplo, cuando una persona sale de la casa y no lleva un arma es porque cree que la otra gente tampoco sale a mano armada, aunque siempre hay una posibilidad de que alguien robe o mate, la gente tiene la percepción de que el acuerdo cultural de no estar armado (a) todavía vale como consenso en la sociedad.

Sumándose a las variables ya mencionadas, que explican la percepción de criminalidad, también influyen algunas señales físicas del entorno (presencia de basura en la calle, grafitis o mobiliario urbano en mal estado) y ciertos comportamientos sociales considerados perturbadores de la convivencia (p. ej., beber en el espacio público, prostitución, la presencia de personas 'alborotadoras', los grupos de jóvenes y los(as) indigentes). Los lugares considerados peligrosos también inciden en la percepción de inseguridad (Pérez, 2012). Estos están caracterizados por una falta de iluminación, la existencia de sombras y elementos ambientales o arquitectónicos que disminuyen el dominio visual del espacio o la ausencia de rutas de escape.

La percepción de criminalidad e inseguridad trae consigo diversas consecuencias que afectan la sociedad en general. La primera de ellas es que este fenómeno se ha convertido en un problema en sí mismo no solo por la probabilidad de ser un fuerte obstáculo para la solidaridad y la convivencia, sino también por su capacidad de generar una ola de violencia, ya que el miedo hace que la ciudadanía pida mayor represión, justifique los excesos y omita la importancia del respeto a los derechos humanos y la democracia (Pérez y Milán, 2005).

Una segunda consecuencia es que en la sociedad existe una imagen de deterioro social desde la percepción del delito, y este es otro de los factores que fortalecen el autoritarismo e impulsan reformas y excesos en la punibilidad. La agresividad que adquieren los cuerpos policiacos ante las demandas de una percepción social desfavorable del estado del delito y de la delincuencia ampliamente publicitada por los medios de comunicación, genera una falsa imagen de efectividad que se traduce en legitimidad y apoyo de las grandes masas, deseosas de tranquilidad ciudadana (Pérez y Milán, 2005).

Una tercera consecuencia es que la percepción de criminalidad también tiene una relación clara con el miedo al crimen que experimentan las personas, entre mayor criminalidad se perciba en el ambiente, mayores niveles de temor se van a manifestar. Además, esta va a influir en la percepción sobre la policía y en las actitudes de castigo hacia los y las delincuentes, entre más se confíe en la policía la percepción del crimen va a ser menor, y entre mayor sea la percepción de la criminalidad, mayor va a ser el apoyo que se manifiesta a favor de acciones de castigo más severas contra las personas que cometen actos delictivos (Ruíz y Turcios, 2009). 
Otra consecuencia de la percepción de la criminalidad son las medidas individuales y colectivas de protección y de contraataque que la sociedad asume (Huhn, Oettler y Peetz, 2007). El miedo a la criminalidad y la percepción de la inseguridad lleva a muchos (-as) ciudadanos (-as) a vivir en lugares cerrados, condominios vigilados o casas fortificadas; otros (-as) evitan frecuentar lugares identificados como peligrosos, sean mercados, determinadas calles o ciudades enteras. Aparte de las reacciones defensivas, crece la cantidad de personas que se arman o se organizan en comités de vigilancia.

\section{Medios de comunicación}

Los medios de comunicación ejercen influencia sobre los pensamientos y acciones de las personas. La mayoría de los conocimientos que las personas poseen acerca de las cuestiones públicas y la mayor parte de las preocupaciones que captan su interés, no proviene de la experiencia personal sino de los medios de comunicación que actúan como la principal fuente de información. (D’Adamo y García, 2007).

Una de las teorías que explica la influencia de los medios es la teoría de cultivo, la cual propone que la estar expuesto(a) cotidianamente a la televisión y otros medios de comunicación influye en las creencias generales que las personas tienen sobre la naturaleza del mundo (García-Castro, 2012). Los medios son un sistema de mensajes que proveen patrones de imágenes e ideologías repetitivas, estables y prácticamente ineludibles que afectan con el tiempo de exposición a la audiencia que las consume.

La otra teoría es la de "agenda-setting" (teoría del establecimiento periodístico de temas de discusión), que pretende explicar la influencia principal de los medios de comunicación en la formación de la opinión pública. Consiste en canalizar la atención del público hacia unos repertorios de temas de preocupación general, en detrimento de otros que no se mencionan o destacan, viéndose así delimitadas las fronteras de conocimientos y juicios. (Soto, 2005).

La consecuencia del proceso selectivo que tiene lugar en los medios cuando eligen sus temarios es que la opinión pública considera a dichos problemas como los más relevantes, mucho más que otros que han sido menos tratados (D’Adamo y García, 2007). Las noticias en los periódicos, la televisión e Internet hacen más que señalar la existencia de eventos y problemas. Mediante su selección diaria y el despliegue noticioso influyen las percepciones sobre cuáles son los asuntos más importantes del día.

Es importante mencionar también, que los medios generalmente responden a intereses particulares de un sector específico de la sociedad. En la mayoría de los casos, los canales de televisión son empresas privadas con intereses particulares que buscan construir una opinión pública que los favorezca (Serrano, 2010, como se citó en García, 2012). Sin embargo, el problema no son los medios de comunicación en sí, sino el uso que se les da en la sociedad moderna.

Las noticias sobre delincuencia, garantizan siempre la atención del público lector. A ello se añaden campañas mediáticas particularmente intensas en períodos electorales, (Soto, 2005). Por lo tanto, se observa que los medios pueden ser manipulados por canales específicos o sectores políticos que intentan influenciar el pensamiento y accionar de las personas con el fin de que estas apoyen sus intenciones. A partir de estas intenciones solapadas, los medios muestran datos que no siempre concuerdan con las cifras reales de inseguridad y delincuencia. Restrepo y Moreno (2007) establecen que la proporción de historias de crimen es una función de los medios, el mercado y la época.

Domina en los medios de comunicación masiva una tendencia a sobre representar crímenes violentos (Espinar y Ruíz, 2010), especialmente agresiones físicas contra personas concretas y homicidios o agresiones que presentan contenido sexual, aun cuando, de acuerdo a los datos estadísticos disponibles, la mayor parte de los crímenes cometidos no incluyen violencia personal.

Finalmente, cabe destacar que no todos los medios de comunicación masiva ejercen la misma influencia. En un estudio realizado por Sherman y Etchegaray (2012) se encontró que el único medio relacionado positivamente con la percepción de temor es la televisión; todos los demás no muestran tener una incidencia significativa. Este vínculo exclusivo entre las noticias en televisión abierta y el 
temor se podría explicar por la profusa cobertura que, a diferencia de los otros, este medio alcanza respecto a la delincuencia. Se suma a lo anterior, la espectacularidad con que son mostrados y narrados este tipo de episodios.

Estos mismos autores mencionan que el impacto de la televisión se puede explicar a través de dos vías. La primera es la directa y determina que mientras más horas de noticias en televisión consumen las personas, se incrementa el nivel de miedo a la delincuencia. La segunda forma de incidencia de la televisión es indirecta o mediada, esta explica que en la medida en que las personas sostienen con mayor frecuencia conversaciones originadas en noticias sobre delitos, aumenta su nivel de temor. (Sherman y Etchegaray, 2012).

\section{Discusión}

Los artículos revisados se agrupan en cinco categorías: perspectivas críticas, miedo al crimen, medición de la criminalidad, percepción de la criminalidad y medios de comunicación. La mayor cantidad de trabajos parten de una visión crítica del uso que hacen los sectores dominantes a la percepción y al miedo al crimen.

Se describe cómo la preocupación sobre el crimen no es una característica cotidiana de la subjetividad, sino, una construcción social a partir de eventos extraordinarios expuestos por los medios de comunicación (Molina, 2005). El sentimiento de miedo produce una búsqueda incesante de seguridad que crea desconfianza y lejanía en la población (Amaya, et al 2011), además de apoyar políticas conservadoras y represivas contra la ciudadanía (Varela, 2005). También se hace énfasis en las diferencias de género en la distribución del miedo (Varela, 2008) y en el uso instrumental que hacen los políticos sobre el tema (Becerra y Trujano, 2011; Valdez y Paniagua, 2011).

Que la categoría crítica sea la que más trabajos agrupe no es sorprendente. En general, en América Latina el miedo a la criminalidad ha sido creado y aprovechado por la clase dominante para dividir, someter y dominar a la población. Además, la criticidad sobre los eventos sociales ha sido una característica de la academia latinoamericana, la cual responde a un contexto marcado por la desigualdad y la injustica.

Otra de las categorías que más artículos agrupa es la del miedo al crimen. El estudio de estas problemáticas ha girado en torno a describir mayormente qué es el miedo al crimen (Restrepo y Moreno, 2007), cómo se desarrolla este en la sociedad (Ruiz, 2007), a partir de qué elementos y variables surge (Méndez, et al, 2009), cuáles son sus principales consecuencias tanto a nivel individual como colectivo (Mansilla, 2011), así como también se ha intentado relacionar el fenómeno con otras variables psicosociales con el fin de conocer cuál es su eje central (Muratori y Zubieta, 2013).

El miedo al crimen es un campo que se ha venido estudiando desde finales de los años sesenta. Su estudio ha arrojado datos en los que se encuentra que en la mayoría de las ocasiones, las tasas objetivas de delitos no concuerdan con la percepción subjetiva de la ciudadanía (Vozmediano, et al, 2010), lo que significa que las personas reproducen mayor temor al crimen en comparación con los datos reales sobre la criminalidad.

El énfasis al estudio del miedo se debe a las consecuencias perjudiciales que tiene para la salud mental. La investigación sobre el miedo a la delincuencia también se ha enfocado en describir cómo este fenómeno ha sido utilizado como parte de los procesos políticos de diferentes países. Ha sido una herramienta de la que se han valido algunos gobiernos, utilizándolo como estrategia política con el propósito de manipular a los y las ciudadanas, construir ideologías autoritarias y que las personas adopten estas como propias, favoreciendo el uso de la violencia y otros mecanismos represivos. (Valdez y Paniagua, 2011; Villalta, 2010).

Hay también una gran parte de la investigación dedicada al estudio de la medición del miedo al crimen y la percepción de inseguridad ciudadana (Ruiz, 2010). Se ha intentado crear y describir instrumentos y herramientas que cumplan con criterios de validez y confiabilidad (Vozmediano, 2010). 
Además se busca definir el fenómeno con el fin de que esta 'operacionalización' sea la guía para elegir las variables a medir e intentar describir el tema de interés (Vozmediano, 2008).

Aun así, el balance sobre la medición de la percepción y el miedo al crimen en América Latina no es favorable. Es necesario contar con instrumentos estandarizados que permitan hacer comparaciones entre los países de la región. La dispersión en la creación de medidas hace que todavía no contemos con suficientes datos que transciendan los ámbitos locales en una problemática que es regional. Además, hay que diversificar la metodología utilizada para compensar las carencias que las encuestas de lápiz y papel presentan.

El estudio de estos fenómenos también se ha enfocado en describir qué es la percepción de inseguridad, donde se busca diferenciarlo del fenómeno del miedo al crimen (García, 2012; Rivera, ToroAlfonso y Meléndez, 2013). Se ha hecho un esfuerzo por describir a partir de qué elementos se genera la percepción de inseguridad y cómo esta se expande por la sociedad en general. También se busca explicar las repercusiones que la inseguridad ha tenido en el comportamiento de las personas y el uso que se le ha dado como herramienta de manipulación.

En la percepción de la criminalidad, la gente se siente insegura no solamente por las tasas reales de criminalidad o por la evaluación racional que hagan del peligro. También se sienten amenazados (-as) a causa de los escenarios de inseguridad creados por los discursos sobre violencia y criminalidad (Huhn, 2008). Dentro de las consecuencias más perniciosas se encuentra el ataque defensivo que hacen las personas al sentirse amenazadas, reproduciendo el círculo de violencia en el que se encuentran las sociedades latinoamericanas (Huhn, et al, 2007).

Por último, la investigación sobre la criminalidad también ha dedicado esfuerzos en describir y explicar el papel que juegan los medios de comunicación en mantener y aumentar el miedo al crimen y la percepción de inseguridad ciudadana (Espinar y Ruíz, 2010; Scherman y Etchegaray, 2012). Los medios han utilizado el tema de la delincuencia como una forma de generar temor en la sociedad y que esta esté dispuesta a votar por un candidato (-a) específico (-a), a que apoyen políticas penitenciaras más represivas, adopten discursos autoritarios de derecha y se cree la opinión pública a partir de la información que se difunde sobre delincuencia que hacen estos, la cual muchas veces está alterada.

Los medios de comunicación transmiten mensajes para entretener e impartir visiones de la realidad que hacen que las personas se ajusten a las estructuras sociales. El nuevo control social se ejerce a partir de la manipulación mediática que las empresas de comunicación ejercen sobre la población para cegarlas y distraerlas de una realidad angustiosa en nuestro contexto. Esta forma sutil de control social busca la apatía, la anomia psicológica y el individualismo (Chomsky, 2002). Aun así, el problema no es el medio (el mensajero) sino el mensaje.

El análisis de las investigaciones realizadas genera un panorama del estado del conocimiento. La mayoría de las investigaciones asumen una perspectiva crítica y describen las problemáticas de su entorno. Se conocen los efectos de la percepción y el miedo a la criminalidad. Sin embargo, no se encontraron investigaciones que describan qué podemos hacer para enfrentar el problema.

Es el momento de buscar y probar intervenciones de reducción del miedo al crimen. Latinoamérica está compuesta por países controlados mediáticamente, pero no se han empezado a probar mecanismos y acciones que puedan reducir el sometimiento. Investigaciones con diseños cuasi experimentales que prueben qué estrategias funcionan y cuáles no pueden ser la indicadas en una nueva línea de investigación sobre el tema.

Entre las principales limitaciones de este trabajo se encuentran que el conocimiento científico no se publica mayoritariamente en español. Además, existe la dificultad de clasificar algunos artículos en una sola categoría cuando podrían catalogarse en varias.

En síntesis, la revisión bibliográfica realizada muestra lo que se ha avanzado y los principales desafíos pendientes. Las ciencias sociales comprometidas deben responder a las necesidades de la población en la que se desarrollan. La tarea principal es generar conocimiento científico que permita a las clases populares develar los mecanismos de dominación ideológica en los que se encuentran (Martín-Baró, 1983/2004). Contribuir a quitarse la venda de los ojos. Esa es la principal importancia de este trabajo, labrar ese camino, muchas veces olvidado. 


\section{Bibliografía}

Amaya, Laura., Espinoza, Augustín., \& Vozmediano, Laura. (2011). Relaciones entre el Miedo al delito y el Autoritarismo de Derecha en estudiantes universitarios de Lima-Perú. Boletín de Psicología, 103, 7-28.

Ayala, Edgardo., \& Chapa, Joana. (2012). La inseguridad y la demanda por entretenimiento: evidencia para las áreas metropolitanas de Monterrey, Guadalajara y León. EconoQuantum, 9(1), 135-148.

Becerra, Mariana., \& Trujano, Patricia. (2011). Percepción de inseguridad pública y justificación de la violencia de Estado en un grupo de habitantes del Estado de México: análisis de argumentos. Acta Colombiana de Psicología, 14(2), 35-43.

Browne, Magdalena., \& Tomicic, Visnja. (2007). Crimen y temor: el rol de los medios. Cuadernos de información, 20, 21-36.

Carrión, Fernando., \& Núñez, Jorge. (2006). La inseguridad en la ciudad: hacia una comprensión de la producción social del miedo. EURE, 32(97), 5-16.

Chomsky, N. (2002). La Propaganda y la opinión pública. Barcelona: Crítica.

Coronado, David. (2006) ¿Realmente sabemos lo que hacemos cuando creemos combatir la delincuencia? Territorios, 15, 33-52.

D’Adamo, Orlando., \& García, Virginia. (2007). Medios de comunicación de masas y percepción social de la inseguridad. Boletín de Psicología, 90, 19-32.

Espinar, E., \& Ruíz, R. (2010). El crimen en los programas informativos de la TV española. Cuadernos de información, 26, 65-76.

Fonseca, K., \& Sandoval, C. (2005). Medios de comunicación e (in)seguridad ciudadana en Costa Rica. San José: Programa de las Naciones Unidas para el Desarrollo.

García, Cruz. (2012). La estructura de la percepción de la inseguridad pública. Liberabit. Revista de Psicología, 18(1), 37-44.

García-Castro, Juan Diego. (2012). Percepción de criminalidad en Costa Rica: clases sociales, televisión e ideología. Becas de Investigación. Serie Documentos de Trabajo, Recuperado de http://biblioteca.clacso.edu.ar/clacso/becas/20120509124519/garciacastro.pdf

Gómez, Ricardo. (2012). Percepciones sobre el crimen y aprobación presidencial en México antes y después de la transición de 2000. Sociológica, 27(75), 95-123.

Gómez, Ricardo. (2013). Calificando al Presidente y percibiendo el aumento del crimen en México. Perfiles Latinoamericanos, 42, 31-53.

Guédon, Jean-Claude. (2011). El acceso abierto y la división entre ciencia "principal” y "periférica". Crítica y Emancipación, 6, 135-180.

Guerrero, Rodrigo., Gutiérrez, María., Fandiño-Losada, Andrés., \& Cardona, Sonia. (2012). Sistema de indicadores comparables de convivencia y seguridad ciudadana: un consenso de países. Revista Panamericana de Salud Pública, 31(3), 253-259.

Huhn, Sebastián. (2008). La percepción social de la inseguridad en Costa Rica, El Salvador y Nicaragua. Revista de Ciencias Sociales (Cr), 4(122), 149-165.

Huhn, Sebastián., Oettler, Anika., \& Peetz, Peter. (2007). La construcción de realidades inseguras. Reflexiones acerca de la violencia en Centroamérica. Revista de Ciencias Sociales (Cr), 3-4(117118), 73-89.

Liebnitzky, Jan., \& Montero, Maritza. (2013). Miedo al crimen en estudiantes de la ciudad de Caracas. Psicología y Sociedad, 25(1), 152-162.

Mansilla, Marcela. (2011). Las marcas del miedo urbano. Sociedad y equidad, 2, 245-265.

Martín-Baró, Ignacio. (1983/2004). Acción e ideología. Psicología social desde Centroamérica. El Salvador: UCA Editores.

Martínez, Jesús., \& Labatut, Bernard. (2005). El sentimiento de inseguridad en la Unión Europea. Una aproximación desde las encuestas de opinión pública. Política y Sociedad, 42(3), 157-184. 
Méndez, José., Villar, Alberto., \& Becerril, Teresa. (2009). Un acercamiento al sentimiento del miedo y su incidencia en la reconfiguración de los espacios sociales. Urbano, 12(19), 79-92.

Molina, Lucía. (2005). Mitos en torno a la criminalidad. Reflexiones, 84(1), 41-47.

Muñoz, M. (2012). El discurso periodístico sobre inseguridad: el uso político-electoral del debate mano dura versus garantismo. (Lineamientos para un modelo interpretativo). Reflexiones, 223-229.

Muratori, Marcela., \& Zubieta, Elena. (2013). Miedo al delito y victimización como factores influyentes en la percepción del contexto social y clima emocional. Boletín de Psicología, 9, 7-18.

Pérez, César., \& Milán, Guillermo. (2005). Los niveles de percepción de la criminalidad en la República Dominicana: caso de las provincias de la Romana, San Domingo y el Distrito Nacional. Ciencia y Sociedad, 30(3), 510-539.

Pérez, Félix. (2012). Diferencias entre los usuarios de seis parques públicos en Barcelona según el nivel de seguridad percibida en el barrio. Athenea Digital, 12(1), 55-66.

Programa de Naciones Unidas para el Desarrollo, PNUD. (2013). Informe Regional de Desarrollo Humano 2013-2014. Nueva York: PNUD.

Pyszczek, Óscar. (2012).Los espacios subjetivos del miedo: construcción de la estigmatización espacial en relación con la inseguridad delictiva urbana. Revista Colombiana de Geografía, 21(1), 41-54.

Reguillo, Rossana. (2008). Sociabilidad, inseguridad y miedos. Una trilogía para pensar la ciudad contemporánea. Alteridades, 18(36), 63-74.

Restrepo, Elvira., \& Moreno, Álvaro. (2007). Bogotá: ¿más crimen?, ¿más miedo? Desarrollo y Sociedad, 59, 165-214.

Rivera, Christian., Toro, José., \& Meléndez, Limary. (2013). Minorías frente al alza en la criminalidad: percepción de seguridad de la comunidad lesbiana, gay, bisexual y transgénero (LGBT) en Puerto Rica. Revista Puertorriqueña de Psicología, 24 (2), 1-14.

Rottenbacher, Jan Marc., Amaya, Laura., Genna, Karen., \& Pulache, Maribel. (2009). Percepción de inseguridad ciudadana y su relación con la ideología política en una muestra de habitantes de la ciudad de Lima. Revista Española de Investigación Criminológica, 4(7), 1-22.

Ruíz, Jose. (2007). Cultura ciudadana, miedo al crimen, y victimización: un análisis de sus interrelaciones desde la perspectiva del tejido social. Acta Colombiana de Psicología, 10(1), 65-74.

Ruíz, Jose. (2007). Procesos sociales relacionados con el miedo al crimen, la satisfacción con la policía y la victimización: El caso de la cultura ciudadana. International e-Journal of Criminal Science, $1(1), 1-29$.

Ruíz, Jose. (2010). Eficacia colectiva, cultura ciudadana y victimización: un análisis exploratorio sobre sus relaciones con diversas medidas del miedo al crimen. Acta Colombiana de Psicología, 13(1), 103-114.

Ruíz, Jose., \& Turcios, Alfredo. (2009). Percepción de seguridad, victimización y cultura ciudadana: sus relaciones en cinco contextos iberoamericanos. Pensamiento Psicológico, 6(13), 193-202.

Ruíz, Rafael. (2007). Estadísticas oficiales vs. percepción ciudadana de la inseguridad: el subregistro delictivo. Salud Pública de México, 49, 141-143.

Salazar, Robinson. (2008). Mercado, crimen y miedo: El eje de la incertidumbre en Latinoamérica. Quórum Académico, 5(1), 143-165.

Salazar, Robinson. (2009). La nueva estrategia de control social. Miedo en los medios y terror en los espacios emergentes. Quórum Académico, 6(2), 105-123.

San Juan, César., Vergara, Anabel., \& Germán, Isabel. (2005). Propiedades psicométricas de un cuestionario para la evaluación de la calidad de vida urbana y el miedo al delito. Revista Española de Investigación Criminológica, 3, 1-13.

San Martín, Carlos. (2013). Las representaciones sociales de la seguridad ciudadana en los vecinos de la Comuna de Melipilla, Chile. Psicoperspectivas, 12(1), 72-94.

Sherman, Aandrés., \& Etchegaray, Nicolle. (2012). Consumo de noticias y temor al delito en Chile. Estudios sobre el Mensaje Periodístico, 19(1), 563-575. 
Sillano, Mauricio., Greene., Margarita., \& Ortúzar, Juan de Dios. (2006). Cuantificando la percepción ciudadana en barrios de escasos recursos. EURE, 32(97), 17-35.

Soto, Susana. (2005). La delincuencia en la agenda mediática. Reis: Revista Española de investigaciones sociológicas, 112(5), 75-130.

Soto, Susana. (2005). La influencia de los medios en la percepción social de la delincuencia. Revista Electrónica de Ciencia Penal y Criminológica, 07-09, 1-46.

Valdez, Andrés., \& Paniagua, Abraham. (2011). Criminalidad, inseguridad pública y comportamiento de los electores: un análisis del proceso electoral estatal 2010 en Ciudad Juárez, Chihuahua. Estudios Fronterizos, nueva época, 12(23), 49-78.

Varela, Cecilia. (2005). ¿Qué significa estar seguro? De delitos, miedos e inseguridades entre los adultos mayores. Cuadernos de Antropología Social, 22, 153-171.

Varela, Cecilia. (2008). Adultas mayores, espacio público y violencia moral: representaciones sociales de la crisis de la "seguridad" en la Argentina desde una perspectiva de género. Mora (Buenos Aires), 14(1), 72-86.

Vilalta, Carlos. (2010). El miedo al crimen en México. Estructura lógica, bases empíricas y recomendaciones iniciales de políticas públicas. Gestión y Política Pública, 19(1), 3-36.

Vozmediano, Laura., \& San Juan, César. (2006). Empleo de Sistemas de Información Geográfica en el estudio del Miedo al Delito. Revista Española de Investigación Criminológica, 2(4), 1-11.

Vozmediano, Laura., San Juan, César., \&Vergara, Ana Isabel. (2008). Problemas de medición del miedo al delito. Revista Electrónica de Ciencia Penal y Criminología, 10(7), 1-17.

Vozmediano, Laura. (2010). Percepción de inseguridad y conductas de autoprotección: propuestas para una medición contextualizada del miedo al delito. Eguzkilore, (24), 203-237.

Vozmediano, Laura., Vergara, Ana Isabel., \& San Juan, César. (2010).El estudio científico del miedo al delito: algunas reflexiones sobre un fenómeno urbano, mediático y político. International e-Journal of Criminal Science, 2(4), 1-20.

Vuanello, Roxana. (2005). Violencia e inseguridad urbana: La victimización de los jóvenes. Fundamentos en Humanidades, 6(1), 135-157.

Vuanello, Roxana. (2006). Un nuevo instrumento de evaluación psicológica: el cuestionario de inseguridad urbana (CIU). Interdisciplinaria, 23(1), 17-45. 